\title{
DEMOCRATIZAÇÃO DE ARQUIVOS EM BIBLIOTECAS DIGITAIS E HEMEROTECAS: UM CAMINHO PARA HISTÓRIAS OU MICRO HISTÓRIAS DA TRADUÇÃO NO BRASIL
}

\author{
Marie Hélène Catherine Torres 1 \\ 1-Universidade Federal de Santa Catarina, Florianópolis, Santa Catarina, Brasil
}

\begin{abstract}
Resumo: O presente artigo apresenta, em primeiro lugar, o estado da arte da História da Tradução no Brasil, considerando os projetos de publicações coletivas e os poucos projetos digitais que temos colocado online com a colaboração de alguns colegas, como o Dicionário de Tradutores Literários no Brasil, que foi colocado online em 2005 e que visa mapear tradutores literários no Brasil e definir seu perfil ou ainda o site Mnemosine online desde 2015, que abriga resultados obtidos com pesquisas financiadas pelo CNPq. Em segundo lugar, discuto do acesso às fontes primárias no Brasil, questão crucial das bibliografias, catálogos e acervos disponibilizados para os pesquisadores que desejam elaborar uma História da Tradução a partir de bases de dados digitais. E finalmente, proponho algumas vias possíveis para escrever a História ou MicroHistória da Tradução no Brasil a partir de arquivos digitalizados.
\end{abstract}

Palavras-Chave: Micro histórias da Tradução no Brasil; Arquivos digitais.

\section{DEMOCRATIZATION OF ARCHIVES IN DIGITAL LIBRARIES AND NEWSPAPER LIBRARY: A PATH TO HISTORIES OR MICRO HISTORIES OF TRANSLATION IN BRAZIL}

\begin{abstract}
This article presents, in the first place, the state of the art of Translation History in Brazil, considering the collective publication projects and the few digital projects that we have put online with the collaboration of some colleagues, such as the Dictionary of Literary
\end{abstract}


Translators in Brazil, which was put online in 2005 and aims to map literary translators in Brazil and define their profile or even the Mnemosine online site since 2015, which houses results obtained from research funded by CNPq. Secondly, I discuss the access to primary sources in Brazil, a crucial issue of bibliographies, catalogues and collections made available to researchers who wish to elaborate a History of Translation from digital databases. And finally, I propose some possible ways to write the History or Micro-History of Translation in Brazil from digitized archives.

Keywords: Micro Histories of Translation in Brazil; Digital Archives.

Faire l'histoire de la traduction, c'est redécouvrir patiemment ce réseau culturel infiniment complexe et déroutant dans lequel, à chaque époque, ou dans des espaces différents, elle se trouve prise. Et faire du savoir historique ainsi obtenu une ouverture de notre présent.

(L'épreuve de l'étranger, Antoine Berman)

Reunir todo o conhecimento da humanidade tem sido sempre um grande desafio ao longo da história. Por exemplo, A Enciclopédia (L'Encyclopédie ou Dictionnaire raisonné des sciences, des arts et des métiers, par une Société de Gens de lettres) foi publicada entre 1751 e 1772 por Diderot e d'Alembert. Contém 17 volumes de texto e 11 volumes de pranchas, contendo 75.000 artigos escritos por mais de 140 colaboradores, destinada a recolher e difundir em "prosa clara e acessível" os frutos do conhecimento e do saber até então acumulados. Os 28 volumes da Enciclopédia estão disponíveis em versão digital no site da Académie des Sciences Françaises.

A digitalização do patrimônio cultural da humanidade permite preservar as obras de autores, intelectuais e artistas e assegurar sua ampla divulgação. São livros acessíveis a todos, em qualquer lugar e a qualquer momento, gratuitamente. E o que não é de domínio público não está disponível na Web.

Em Paris, a Biblioteca Nacional da França (a BNF) criou o site Gallica, um sistema que armazena mais de um milhão de livros, 2,5 milhões de impressos, etc. No blog da Gallica, encontramos, a título de amostra, o das Relações França-Brasil que festeja em 2019, dez anos de parceria. 
No Brasil, há vários grandes projetos de memória digital, como veremos, e de acordo com Bruna de Freitas e Mariana Georgetti Valente (8), as questões problemáticas relativas à digitalização são de quatro tipos principais: 1) questões técnicas (software, meta-dados e a base tecnológica da web semântica; 2) direitos de propriedade intelectual; 3) políticas institucionais e 4) o financiamento.

Um dos primeiros projetos no Brasil foi lançado na Universidade de São Paulo (USP), em 2006, disponibilizando na web 3.000 títulos de um acervo de 40.000 títulos do bibliófilo José Mindlin. Assim, a BBM Digital, Biblioteca Brasiliana Guita e Mindlin, cujo projeto obteve uma doação de R \$1,8 milhão do Ministério da Cultura e da Fundação FAPESP. Isto é praticamente nada comparado aos 14 milhões de euros alocados anualmente para o projeto francês Gallica.

Pretendo, portanto, dividir meu artigo em três partes principais. $\mathrm{Na}$ primeira parte, tentarei, mostrar o estado da arte da História da Tradução no Brasil, considerando os projetos de publicações coletivas e os poucos projetos digitais que temos colocado online com a colaboração de alguns colegas, como o Dicionário de Tradutores Literários no Brasil, que foi colocado online em 2005 e que visa mapear tradutores literários no Brasil e definir seu perfil ou ainda o site Mnemosine online desde 2015, que abriga resultados obtidos com pesquisas financiadas pelo CNPq. Na segunda parte, sobre o Estado da Arte, desta vez, concernente ao acesso às fontes primárias no Brasil, discutirei a questão crucial das bibliografias, catálogos e acervos disponibilizados para os pesquisadores que desejam elaborar uma História da Tradução a partir de bases de dados digitais. E finalmente, na terceira parte, proponho algumas vias possíveis para escrever a História ou Micro-História da Tradução no Brasil a partir de arquivos digitalizados.

Inicio com os grupos de pesquisa em Estudos de Tradução ligados a várias universidades do Brasil (PGET/UFSC, POET/UFC, POSTRAD/UnB, a Pós-graduação em Letras/UFPR que tem uma linha de pesquisa em Estudos da Tradução, e a PPLetra/USP) que se reuniram várias vezes desde 2014 para pensar e desenvolver uma História da Tradução Nacional. Esse projeto de fazer, de pro- 
duzir uma História da Tradução sempre nos pareceu um empreendimento colossal, e, sem precedentes no Brasil, pois não há, até agora, em 2019, nenhuma História da Tradução no sentido mais amplo do termo.

Em primeiro lugar, gostaria de dizer que considero que a História da Tradução é a história das ideias, das mentalidades e da cultura num determinado espaço e tempo, partindo de uma perspectiva histórica ou antes micro-histórica, como veremos a seguir. Na minha opinião, elaborar uma história da tradução não significa necessariamente, como a idealizamos no Brasil até agora, criar uma obra sintética, a mais exaustiva possível, ou mesmo uma história que siga critérios seculares (Milton e Silva-Reis), mas sim, no caso específico do Brasil, significa produzir uma ou mais micro -história(s) de tradução. A primeira pergunta, talvez, que o historiador-pesquisador poderia fazer a si mesmo é: por onde começar? A única certeza que o historiador da tradução pode ter é que ele ou ela deve considerar as mudanças que ocorrem em outras esferas do conhecimento e da sociedade, a fim de compreender as modificações dentro do sistema literário, e na literatura traduzida. Essas mudanças, ao meu ver, estão diretamente ligadas à evolução digital e, em particular, à preservação do patrimônio cultural. E a história da tradução é a história da relação entre vários parâmetros como línguas, culturas, gêneros, temas, contexto político e social, imprensa, editores, escritores, tradutores, etc. É uma relação complexa entre estes parâmetros com a cultura-fonte e a cultura-alvo, uma vez que permite uma ampla gama de possibilidades para definir seu objeto de estudo. E quando falo de História da Tradução, refiro-me, na verdade, à História da Tradução Literária. Não há História da Tradução no Brasil como tal, como por exemplo: Les traducteurs dans l'histoire de Jean Delisle (1995), Portraits de traductrices, Delisle (1999) ou L'Histoire de la traduction. Repères historiques et culturels de Ballard Michel (2013), por exemplo. Tampouco há História de Tradução no Brasil como: L'Histoire des traductions en langue française da Editora Verdier (4 volumes), The Oxford History of Literary Translation in English publicado por Oxford University 
Press (5 volumes) ou a Historia de la traducción en España de Francisco Lafarga e Luis Pegenaute (eds.) publicada pela Biblioteca Virtual Miguel de Cervantes, 2008 (PDF no site).

$\mathrm{O}$ editor dos volumes franceses, Yves Chevrel, na sua Conferência intitulada "Histoire des traductions, histoire culturelle" [História das Traduções, História Cultural] na universidade de Toulouse II - Le Mirail em 22 de novembro de 2013, uma conferência reproduzida integralmente no site da editora Verdier, especifica, entre outras coisas, que o projeto de publicar os quatro volumes da História das Traduções em língua francesa recebeu uma verba de 300.000 euros para pagar salários, fazer pesquisas, ir às bibliotecas e que, por outro lado, eles escolheram a frequência secular. Menciona, no seu discurso, que se trata de uma história de traduções, no plural, porque se interessa não só por traduções literárias, mas também por traduções de vários campos do conhecimento. Chevrel apresenta também os periódicos que dedicaram um número especial à tradução e que ele considera como marco histórico:1989 = A Revue de Littérature Comparée publica um número especial sobre a questão das traduções, onde se apresenta o programa de Van Braght e Lambert para informatizar as referências das traduções francesas entre 1810 e 1840 . O que era revolucionário na época, uma vez que não havia Internet em 1989! Nesta edição havia também a questão do discurso das traduções, o papel dos prêmios literários estrangeiros em que surgiram problemas culturais; 1997 = edição da Revue d'Histoire Littéraire de la France sobre a tradução como património cultural; $2006=$ A revista alemã Romanistische Zeitschrift für Literaturgeschichte/ Cahier de história das literaturas romanas com o artigo de Chevrel e Masson "vers une histoire des traductions en langue française". Assim, para escrever uma história da tradução no Brasil, também é necessário definir quais aspectos da história da tradução serão estudados. Quais seriam os objetivos ? Quais seriam as primeiras perguntas a serem respondidas?

Um estudo bastante recente de Lieven D'hulst, Essais d'histoire de la traduction: Avatars de Janus. Paris: Garnier, 2014, em seu 
primeiro capítulo, apresenta as teorias e os métodos da historiografia, com base nas seguintes questões:

- Quem traduz? O tradutor: pesquisa possível sobre: o seu estatuto e visibilidade, sua formação, suas condições de trabalho e remuneração, etc.

- O que se traduz? Quais as obras traduzidas: número, língua original, escolha das obras a traduzir, obstáculos à tradução, condições de publicação, censura, discrepâncias entre o corpus traduzido e o cânone literário do país de origem.

- Onde foram escritas as traduções? E publicadas e por qual editora?

- Que apoio recebeu a tradução? Houve censura? Qual o poder da tradução?

- Por que existem algumas traduções e outras não? Porque é que as traduções se comportam de tal forma?

- Como se traduz? Incluindo reflexões teóricas sobre a tradução dos tradutores.

- Em que ponto da história de um sistema cultural e literário aparecem as traduções? Com que frequência?

- Qual o papel cultural da tradução?

- Quais são os efeitos sobre a língua: o papel da tradução na evolução da linguagem escrita ou no desenvolvimento de ferramentas lexicográficas?

- Quais os efeitos produzidos na literatura: o papel da tradução na formação e evolução da literatura "original"?

- Quais os efeitos produzidos na sociedade: para quem se traduziu ao longo dos séculos? Recebimento de obras traduzidas para o público, influência sobre outras áreas da cultura local, identidade nacional, religião, etc.

Veremos a seguir como poderia se pesquisar no Brasil a partir dos últimos questionamentos de Lieven D'hulst.

Gostaria de continuar minha análise mostrando rapidamente dois projetos coletivos de História da Tradução no Brasil, ou melhor, 
projetos editoriais, o Projeto Editorial da Coleção Engrenagens e Projeto Editorial da Coleção TransLetras. A coleção Engrenagens é uma coleção de Estudos de Tradução que iniciou sua publicação em outubro de 2015 com o livro História da Tradução: ensaios de teoria, crítica e tradução literária, sendo o primeiro volume de uma coleção inédita no Brasil publicada pela editora Pontes. São vários volumes publicados pela editora da Coleção, a professora e pesquisadora Germana Henriques Pereira de Sousa, da Universidade de Brasília, especialista em literatura e tradução, que organiza, há alguns anos, um seminário anual sobre história da tradução e da tradução literária na Universidade de Brasília, e que está em sua quinta edição, se não me engano. Há também o Projeto Editorial TransLetras, cujos diretores de coleção são Luana Ferreira de Freitas, Walter Costa e Marie Helene C. Torres. A coleção tem quatro edições publicadas desde março de 2015. Os volumes focam antologias traduzidas, a questão da tradução comentada, a poesia traduzida e Machado de Assis traduzida. O quinto volume sobre Tradução e Migração está em preparação. Anda existem várias publicações digitais no Brasil como por exemplo o blog da Marlova Aseff sobre os Poetas-tradutores e a formação do cânone da poesia traduzida no Brasil. https://poesiatraduzida.com.br/author/user/.

Com relação à nossa expertise em publicações digitais, estou realizando pesquisas sobre a história da tradução e dos tradutores com a publicação em coedição com Walter Costa e Andreia Guerini do Dicionário de Tradutores Literários no Brasil Online (http:// www.dicionariodetradutores.ufsc.br/pt/index.htm). O objetivo deste dicionário de tradutores é mapear tradutores literários no Brasil e definir seus perfis. Trezentos tradutores estão atualmente listados no dicionário. Um dos efeitos procurados é que o dicionário dê certa visibilidade a este intermediário cultural que é o tradutor.

Desde 2015, existe também a publicação online da Anthologie Mnemósine (https://mnemosineantologias.com), resultado da pesquisa financiada pelo $\mathrm{CNPq}$. Na mitologia grega, Mnemósine apaixonou-se por Zeus, o mais poderoso deus do Olimpo. Para atraí-lo, ela aproveitou dos seus talentos de contadora de história 
e o seduziu por nove noites sucessivas. Poucos meses depois, ela deu a vida às nove musas, que também são conhecidas sob o nome de "Meninas da memória" ou de Musas protetoras da Ciência, das Artes e Letras. São elas: Calliope, Thalia, Melpomene, Euterpe, Polymnia, Clio, Terpsichore, Urania e Erato. Criadora da linguagem, a deusa escreveu um livro guardado por Cronos, o deus do tempo, sobre a história que passava, transcrevendo o que as musas lhe contavam. Assim, Mnemósine é a memória do passado! Ela é a história que continua sendo escrita! Portanto, o site Mnemósine resgata a memória para escrever nossa história da Tradução e reúne em antologias obras e autoras que, em sua maioria, nunca foram traduzidas no Brasil, com verbete contendo bibliografia, excerto de uma obra da escritora e a sua tradução num texto bilíngue. Outro projeto de obras digitais pode ser encontrado na página do Mestrado e Doutorado em Estudos de Tradução (da PGET/UFSC) que disponibiliza uma biblioteca digital. Como podemos ver, novas formas de divulgação de conteúdos científicos surgiram, graças a documentos digitalizados e que permitem: mais velocidade, mais leitores, em qualquer lugar, em menos tempo.

Chego agora ao meu segundo ponto, ou seja, a questão das fontes primárias disponíveis atualmente no Brasil. É bastante difícil comparar a situação do Brasil com o que outras culturas conseguem fazer, pois, por exemplo, os pesquisadores franceses têm a sua disposição os arquivos e coleções do Depósito Legal francês desde 1537. A indústria editorial brasileira começou sua história com a chegada da família real portuguesa em 1808 no Rio de Janeiro, que veio com a Biblioteca Real de Bragança. Até então, até 1808, toda a atividade editorial no Brasil-Colônia era proibida, para que a disseminação de ideias e opiniões não comprometesse a censura existente.

No que diz respeito, então, aos documentos primários, ou seja, catálogos, repertórios, bibliografias e bases de dados, jornais, periódicos, almanaques, documentos produzidos por testemunhas diretas, artigos, relatórios, conferências, teses, memórias redigidas a partir de dados originais, correspondência, o Brasil tem sido muito mais rico e diversificado em recursos nos últimos anos do que 
parece. Existem também, como é sabido, documentos gráficos primários (desenhos, fotos), gravações de áudio e vídeo, bem como documentos geográficos (Google Earth). Os documentos primários em PDF constituem um caso a parte, na medida em que podem conter textos e imagens.

A respeito do estado da arte do acesso a fontes primárias, o Brasil está muito aquém da gigantesca biblioteca digital dos Estados Unidos, a Digital Public Library of America (DPLA, 2013) ou mesmo da biblioteca digital europeia, Europeana Collections (2008), cuja “missão é transformar o mundo através da cultura, construir um rico património cultural europeu e dar às pessoas a oportunidade de o reutilizar facilmente, para pesquisa, aprendizagem pessoal ou simplesmente por diversão". Outras bibliotecas no mundo investirem massivamente em digitalização dos seus acervos. Por exemplo, a biblioteca DigitaVaticana foi fundada em 2013 para promover a conversão dos manuscritos da Biblioteca Vaticana em formato digital. Pretende contribuir com a digitalização de mais de 80.000 manuscritos mantidos na Biblioteca Vaticana, 5.000 gravuras, desenhos e placas, 9.000 incunábulos, 100.000 unidades de arquivo, dezenas de milhares de edições dos séculos XVI e XVII. Digitalizou por enquanto 17.259 manuscritos. A WDL, biblioteca digital mundial, um projeto de colaboração entre a Biblioteca do Congresso dos EUA, a UNESCO, 118 bibliotecas no mundo, 20 museus, etc., consultável em Árabe russo, mandarim, inglês, espanhol, francês e português. A primeira página do site da Biblioteca Pública Digital Norte-Americana anuncia:

"Discover 33,306,626 images, texts, videos, and sounds from across the United States" [Descubra 33,306,626 imagens, textos, vídeos e sons de todos os Estados Unidos] enquanto a Europeana anuncia 58,077,411 obras de arte, objetos, livros, vídeos e sons de toda a Europa.

Quanto ao conjunto das coleções da BN do Rio, estas representam cerca de 10 milhões de documentos impressos e especializados (livros, periódicos, manuscritos, mapas, fotografias, imagens, etc.). Criada em 1810, é a maior biblioteca da América Latina e 
a $7^{\text {a }}$ maior do mundo. A BNDigital foi criada em 2006 e possui 2.078.154 impressos digitais com acesso livre e gratuito. A abordagem seguida até agora pelos pesquisadores no Brasil, entre os quais me incluo, é a de comparar o incomparável como mostram os números. Não temos até hoje no Brasil recursos de referência primárias iguais aos de países-cultura como a França, os Estados Unidos ou todos os países da Europa juntos. Nem em quantidade nem em qualidade de conservação. A impressão de livros começou há apenas 2 séculos no Brasil! Talvez, uma das abordagem mais viável para escrever uma História da Tradução no Brasil seria a de pesquisar a partir de fontes primárias existentes e não persistir em seguir usando abordagens idealizadas ou ideais, evitando assim lamentar-se sobre a falta de fontes primárias confiáveis, o que paralisou toda e qualquer abordagem de história da tradução concreta até agora. Os desafios para o desenvolvimento da digitalização das coleções documentais e periódicas das "instituições de memória", ou seja, bibliotecas, museus e outros arquivos no Brasil, são enormes. Basta fazer um breve inventário do que realmente existe em 2019, com o objetivo de realizar pesquisas para criar uma História da Tradução no Brasil:

1. Biblioteca Nacional Digital (http://bndigital.bn.br/)

Propõe projetos específicos: rede brasileira de memória virtual (sobre as expressões culturais das artes, música, literatura e história do país e suas regiões); o portal digital França no Brasil entre as bibliotecas nacionais do Brasil e da França; Jornais e literatura; Guerra do Paraguai; Coleção Thereza Christina (Coleção de fotografias do Imperador D. Pedro II); Hemeroteca brasileira de jornais digitais (coleção de periódicos - jornais, revistas, almanaques, boletins, etc.).

2. Biblioteca Brasiliana Guita e José Mindlin

3. Laboratório de digitalização de obras raras da Fiocruz

4. Biblioteca Digital do Senado Federal

5. Biblioteca Digital do Museu Nacional

6. Real Gabinete Português de Leitura 
7. Biblioteca Digital Brasileira de Teses e Dissertações (BDTD)

8. Bibliotecas digitais de teses e dissertações de universidades federais (somente na PGET/UFSC foram defendidas até maio de 2019: 279 dissertações de mestrado e 108 teses de doutoramento)

9. O site "Literatura Digital UFSC - biblioteca de literaturas da língua portuguesa"

O exemplo que considero nessa parte do artigo é o setor digital da BNDigital do Rio de Janeiro que foi oficialmente lançada em 2006 com o objetivo de aumentar e democratizar o acesso da população aos documentos de memória nacional através de sua digitalização e disponibilização no seu site, principalmente a hemeroteca, onde é mantida a maior coleção de revistas e jornais do Brasil, com mais de 5.000 periódicos. Muitos jornais e almanaques circulavam no Rio de Janeiro no século XIX, tanto que as principais livrarias anunciadas no Jornal do Commercio na década de 1870 (Ferreira 45-6) eram as seguintes: Garnier - Rua do Ouvidor, n. 69; Enciclopedica - Rua Gonçalves Dias, n. 72 ; E. e. e H. Laemmert - Rua do Ouvidor, n. 68; Cruz Coutinho - Rua São José, n. 75; Casa de uma Porta Só - Rua São José, n. 69; Luso-brasileira - Rua da Quitanda, n. 30; Dupont e Mendonça - Rua Gonçalves Dias, n. 75; Clássica - Rua Gonçalves Dias, n. 54; Econômica - Largo do Paço C; Correa de Mello - Rua do Ouvidor, n. 153. Por exemplo, O Jornal do Commercio, que usei como fonte primária, foi criado em 01/10/1827 no Rio de Janeiro por um francês, Pierre Plancher, fugido da França porque era bonapartista. Este jornal foi digitalizado para o período de 1827 a 1890, abrangendo o Império e o período de escravidão. Notese também que, a fim de aumentar o número e o contato com os leitores, os jornais e os tipógrafos-livreiros tinham os seus próprios almanaques. Todos os jornais e almanaques citados foram digitalizados e colocados online gratuitamente.

A BNDigital do Rio de Janeiro colocou online os almanaques cujo papel era difundir conhecimento e habilidades práticas, tornan- 
do-se rapidamente um meio indispensável de venda de impressos no século XIX. O almanaque, periódico publicado uma vez por ano e contendo, além de um calendário, efemérides e outras informações e textos úteis para o leitor, é sem dúvida, ao lado dos impressos religiosos, a mídia mais difundida no Rio de Janeiro no século XIX. O almanaque mais famoso da época era o da Librairie Garnier no Rio de Janeiro, parte integrante de uma política editorial que visava aumentar a produção e circulação das publicações da Garnier no Brasil. Os temas eram variados: o estudo da língua, do território, da religião e da cultura. Segundo Chartier e Lüsebrink (Prefácio), o almanaque popular se tornou um verdadeiro gênero editorial. Tomemos o exemplo do Almanach Garnier de 1903. Encontramos nele varias traduções de peças de teatro, de romances, de literatura infanto-juvenil. Algumas trazem o nome do tradutor, outras nem mencionam que se tratam de traduções. Algumas são traduções portuguesas, outras brasileiras. O tradutor K. de Avellar, que aparece varias vezes no almanach, é um tradutor fictício, de acordo com Denise Bottmann, que pesquisou sobre ele. Algumas traduções são apresentadas como traduções modernas. O que será uma tradução moderna? Uma nova tradução? Uma tradução original (no sentido de diferente)? Uma nova tradução em português brasileiro?

Percebe-se que novas práticas documentais permitam maior acessibilidade à documentação e massificação dos corpora disponíveis porque, ao se conectarem à Internet, os historiadores da tradução têm acesso a milhões de documentos digitalizados, a um grande número de inventários de centros de arquivos e catálogos informatizados de bibliotecas. Este é o caso atualmente no Brasil. Os pesquisadores em História da Tradução não podem ou não podem mais ignora-lo, pois, eles têm a oportunidade de consultar diversos tipos de documentação digital útil às suas pesquisas, tais como periódicos, enciclopédias, arquivos abertos, etc.

O que proponho, portanto, é que mais pesquisadores, no Brasil, pensem em trabalhar diretamente com arquivos digitalizados porque a integração da cultura digital nas práticas de pesquisa de hoje já é uma realidade. Eu diria talvez Micro-história em vez 
de História porque a micro-história favorece a descrição densa, a abundância de informações, o cruzamento de fontes e perspectivas, permitindo assim uma "individualização" da investigação. A micro -história sugere que os historiadores se afastem do estudo das massas ou das classes para se interessar de mais perto pelos indivíduos. Seguindo o destino particular de um indivíduo, lançamos luz sobre as características do mundo que o rodeia. Os teóricos italianos da micro-historia (Levi, Ginzburg, Poni) defendem uma redução da escala, a fim de examinar os fenômenos com lupa. Em outras palavras, a micro-história permite revelar e explicar fenômenos históricos com um alcance generalizante que paradoxalmente não pode revelar um estudo da história com um campo de investigação mais amplo, o que lhe dá um grande valor científico. A micro-história passa assim do macro para o micro e centraliza o seu objeto de estudo no indivíduo, na sua trajetória, nas suas estratégias, nas suas experiências.

Por exemplo, posso pesquisar a micro-história dos tradutores de B.L. Garnier, entre outras editoras, examinando os catálogos de vendas e almanaques do editor-livreiro, que são fontes primárias privilegiadas. Uma das hipóteses iniciais possíveis é que essa pesquisa levaria/levará à história do poder dos tradutores e de suas traduções e, mais adiante, ao cânone da literatura brasileira com possíveis reflexões sobre o papel da história do livro traduzido no Brasil no século XIX. Outra hipótese possível/provável é a de uma mudança de ponto de vista, isto é, posso partir do pressuposto de que a história da literatura brasileira é a história da literatura traduzida. Tais pesquisas sobre os tradutores podem explicar o funcionamento das relações de poder entre editores, tradutores e leitores da época e podem até mostrar o grau de antropofagia sócio-político-nacional-cultural frente ao pensamento eurocêntrico e principalmente galocêntrico importado do saber letrado. Outras pesquisas em andamento entre o Brasil e a França podem servir de base, pois, trabalham com a circulação de materiais impressos no século XIX, em cooperação com pesquisadores estrangeiros e fundos brasileiros, como Marcia Abreu, Lucia Granja, etc. 
O fato é que estudos de percursos individuais tem estado intimamente ligado aos das redes, focalizando-se particularmente sobre a evolução das configurações relacionais e sociais ao longo das trajetórias biográficas. Insistir no uso de arquivos físicos de obras e documentos históricos pode revelar uma tradição ultrapassada e não muito adequada ao nosso modo de viver, de pensar e de pesquisar nesse início do século XXI. O arquivamento eletrônico, isto é, o armazenamento a longo prazo de documentos e dados digitais, representa um meio infinito de acesso a documentos raros, esgotados e antigos. A consulta de um arquivo digital facilita as pesquisas, poupando-lhe sobretudo um tempo precioso. Portanto, as bibliotecas digitais tornaram-se dispositivos indispensáveis à nossa contemporaneidade informativa: rapidez e comodidade no acesso aos documentos, socialização dos documentos e preservação digital da memória cultural. Minha sugestão de pesquisa tende para uma proposta de pesquisa em micro-História da Tradução no Brasil, dinâmica, aberta e digital no lugar de uma História da Tradução Tradicional, Estática e Física. Acredito que partir de dados e documentos digitalizados existentes, é ter a opção de começar a escrever uma Micro-História da Tradução no Brasil.

\section{Referências}

\section{Fontes primárias}

Biblioteca Pública Digital da América (DPLA). Disponível em: https://dp.la/. Acesso em: 16/10/2018.

Collaborative and Critique Digital Edition of the Encyclopedia or Dictionnaire raisonné des sciences, des arts et des métiers (1751-1772). Disponível em: http:// 
enccre.academie-sciences.fr/encyclopedie/. Acesso em: 16/10/2018.

Colecções Europeana. Disponível em: https://www.europeana.eu/portal/fr. Acesso em: 16/10/2018.

Hemerotheque Digital. Disponível em: http://bndigital.bn.gov.br/hemerotecadigital/. Acesso em: 16/10/2018.

La France au Brésil. Disponível em: http://bndigital.bn.br/projetos/francebr/. Acesso em: 16/10/2018.

Periódicos literários. Disponível em: http://bndigital.bn.br/projetos/ periodicosliterarios/. Acesso em: 16/10/2018.

Rede Brasileira de Memória Virtual. Disponível em: http://bndigital.bn.br/ projetos/redememoria/. Acesso em: 10/10/2018.

Biblioteca Vaticana digital. Disponível em: http://www.digitavaticana. org/?lang =en._Acesso em: 10/10/2018.

Laboratório de digitalização de obras raras da Fiocruz. Disponível em: http:// www.labdigital.icict.fiocruz.br/. Acesso em: 10/10/2018.

Biblioteca Digital do Senado Federal. Disponível em: http://www2.senado.gov. br/bdsf/._Acesso em: 10/10/2018.

Biblioteca Digital do Museu Nacional. Disponível em: http://www.obrasraras. museunacional.ufrj.br/. Acesso em: 03/10/2018.

Real Gabinete Português de Leitura. Disponível em: http://rgplgead.bibliopolis. info/GeADOPAC/. Acesso em: 03/10/2018.

Biblioteca Digital Brasileira de Teses e Dissertações (BDTD). Disponível em: http://bdtd.ibict.br/vufind/. Acesso em: 03/10/2018.

Bibliotecas digitais de teses e dissertações de universidades federais (http:// 
ppget.posgrad.ufsc.br/biblioteca-da-pget e http://ppget.posgrad.ufsc.br/teses-edissertacoes-pget/).

Literatura Digital UFSC - Biblioteca de literaturas da língua portuguesa. Disponível em: https://www.literaturabrasileira.ufsc.br/. Acesso em: 03/10/2018.

\section{Fontes secundárias}

Abreu, Marcia. Circulação dos impressos: a globalização da cultura no século XIX (1789-1914). Disponível em: http://www.circulacaodosimpressos.iel. unicamp.br/index.php?cd=1\&lang $=$ pt. Acesso em:20/05/2019.

Chartier, Roger; Lüsebrink, Hans-Jürgen (dir.). Pedágio e leitura popular. Impressões de grande circulação e literatura de venda a retalho na Europa, séculos XVI-XIX. Paris: IMEC Éditions/Éditions de la Maison des sciences de l'Homme, 1996.

Dicionário de Tradutores Literários no Brasil Online. Disponível em: http:// www.dicionariodetradutores.ufsc.br/pt/index.htm. Acesso em: 20/05/2019.

Ferreira, Tânia Maria Tavares Bessone da. "Comércio de livros: livreiros, livrarias e impressos”. Revista Escritos 5, Rio de Janeiro: FCRB, 2011.

Freitas, Bruna Castanheira de; Valente, Mariana Giorgette (org). Memórias digitais: o estado da digitalização de acervos no Brasil. Rio de Janeiro: Editora FGV, 2017.

Heimburger Franziska, Ruiz Émilien. "Faire de l'histoire à l'ère numérique: retour d'expériences". Revue d'histoire moderne \& contemporaine, 2011/5 ( ${ }^{\circ}$ 58-4bis), p. 70-89. Disponível em: https://www.cairn.info/revue-d-histoiremoderne-et-contemporaine-2011-5-page-70.htm. Acesso em : 20/05/2019.

Henriques, Germana. História da Tradução. Coleção Engrenagens. 4 volumes. Campinas: Editora Pontes, de 2015. 
Milton, J.; Silva Reis, D. "História da tradução no Brasil: percursos seculares". Revista Translatio, Porto Alegre, $\mathrm{n}^{0} .12$ (2016): 2-42.

O site das escritoras francesas do século XVIII: Disponível em: https:// mnemosineantologias.com/. Acesso em: 20 de outubro de 2018.

Blog da Marlova Aseff sobre os Poetas-tradutores e a formação do cânone da poesia traduzida no Brasil. Disponível em: https://poesiatraduzida.com.br/author/ user/. Acesso em: 20/05/2019.

Lafarca, Francisco; Pegenaute, Luis (Eds.) Historia de la Traducción en España. Salamanca: Editorial Ambos Mundos, 2004.

Torres, Marie Helene et al. Antologia bilingue dos clássicos da teoria da tradução franco-portuguesa. Florianópolis: NUPLITT, 2018. Disponível em: http://ppget. posgrad.posgrad.ufsc.br/biblioteca-da-pget/biblioteca-digital-2-2. Acesso em: 20 de outubro de 2018.

Recebido em: 05/09/2019

Aceito em: 10/12/2019

Publicado em janeiro de 2020

Marie Helene Catherine Torres. E-mail: marie.helene.torres@gmail.com. ORCID: https://orcid.org/0000-0001-9263-0162 